\title{
Patient-Reported Outcomes and Impact of Type 2 Diabetes: A Cross-Sectional Study in the Kingdom of Saudi Arabia
}

This article was published in the following Dove Press journal: Patient Preference and Adherence

\author{
Heather L Gelhorn' \\ Kristina S Boye ${ }^{2}$ \\ Huda Shalhoub (D) \\ Louis S Matza' \\ Jessica B Jordan' \\ Ali Alhammad ${ }^{3}$ \\ Savita B Anand ${ }^{4}$ \\ Aishah A Ekhzaimy $\mathbb{D}^{5}$ \\ Alena Strizek (iD ${ }^{6}$ \\ 'Evidera, Bethesda, MD, USA; ${ }^{2}$ Eli Lilly and \\ Company, Indianapolis, IN, USA; ${ }^{3}$ Eli Lilly \\ and Company, Riyadh, Kingdom of Saudi \\ Arabia; ${ }^{4}$ Evidera, London, UK; ${ }^{5}$ King Saud \\ University, King Saud University Medical \\ City, Riyadh, Kingdom of Saudi Arabia; ${ }^{6}$ Eli \\ Lilly, Sydney, Australia
}

Correspondence: Heather L Gelhorn Evidera, 7I0I Wisconsin Avenue, Suite I400, Bethesda, MD 208|4, USA

$\mathrm{Tel}+$ I 970-363-7333

Email heather.gelhorn@evidera.com
Background: The Kingdom of Saudi Arabia (KSA) has the second highest prevalence of type 2 diabetes mellitus (T2DM) in the Middle East. There is a paucity of research on the experiences and treatment preferences of patients with T2DM in KSA. This study explored Saudi patients' health-related quality of life, eating habits, experiences during Ramadan, and preference between two glucagon-like peptide-1 receptor agonist (GLP-1 RA) treatment devices.

Methods: A cross-sectional, observational study was conducted in three cities in KSA. Participants completed sociodemographic and clinical forms, EQ-5D-5L, Impact of Weight on Self-Perceptions, and a diabetes treatment survey. Participants also viewed instructional videos on GLP-1 RA injection devices and indicated their device preference.

Results: Of the 310 participants, $53 \%$ were male. The mean age was 43 years (range: $30.0-$ 75.0), duration since diabetes diagnosis was 6.3 years (range: $0.2-27.1$ ), the most commonly reported last $\mathrm{HbA} 1 \mathrm{c}$ level was between $\geq 7.1 \%$ and $8 \%$ (45\%). The mean EQ-5D-5L index score was 0.90 , with some participants reporting problems with pain/discomfort $(34.5 \%)$ and usual activities (33.2\%). Patients reported a low-to-moderate impact of weight on self-perception. In preparation for Ramadan, participants sought physician advice on diabetes management $(37 \%)$ and/or increased checks of their blood glucose (37\%). After watching the videos, $89 \%(n=277)$ of participants indicated a device preference, with significantly more preferring the dulaglutide device $(n=186,67 \%)$ over the semaglutide device $(n=91,33 \%)(p<0.0001)$.

Conclusion: This study indicates that T2DM has a significant social, emotional, and behavioral impact on the lives of patients in KSA.

Keywords: Kingdom of Saudi Arabia, patient-reported outcomes, type 2 diabetes, preferences, impacts, health-related quality of life

\section{Introduction}

Type 2 diabetes mellitus (T2DM) is a chronic metabolic disease affecting more than 500 million people worldwide. ${ }^{1}$ The Kingdom of Saudi Arabia (KSA) has the second highest prevalence of T2DM in the Middle East, which represents a serious public health concern due to high levels of morbidity and mortality. ${ }^{2,3}$ Although the prevalence of diabetes in KSA is well documented, the population characteristics, patient-reported impacts associated with diabetes, health-related quality of life (HRQoL), and the treatment preferences of these patients are less well understood.

Sub-optimal treatment of T2DM can result in several health complications such as neuropathy, kidney failure, and cardiovascular events. ${ }^{4,5}$ A recent cross-sectional study conducted among Saudis with T2DM $(n=423)$ demonstrated that $75 \%$ of 
participants had poor glycemic control. ${ }^{6}$ Factors predictive of persistent hyperglycemia included a family history of diabetes, long duration of diabetes, lack of exercise, and excess body weight. Furthermore, a study that analyzed medical records from two diabetes clinics in Riyadh reported that only $19 \%$ of T2DM patients achieved American Diabetes Association (ADA) recommended HbAlc targets, with $70 \%$ reporting two or more cardiovascular risk factors. ${ }^{4}$

Improving patients' medication adherence can result in significant improvements in glycemic control. ${ }^{7}$ An association between medication adherence and HRQoL has been demonstrated among patients with T2DM in KSA. ${ }^{8}$ Additionally, a recent consensus report by the ADA and the European Association for the Study of Diabetes (EASD) suggests that healthcare providers should strive to personalize treatments by addressing patients' concerns about treatments to potentially improve medication adherence., ${ }^{9,10}$ Specifically, the report highlights that among patients with T2DM, patient preference is a "major factor driving the choice of medication." Further, the report notes that preference is influenced by a wide range of treatment attributes, and that treatment attributes (such as the injection devices) can prevent some patients from using a medication even if the medication has been proven effective. Further, patient preference can have an impact on treatment adherence, which contributes to treatment outcomes. ${ }^{11-13}$ Therefore, when making treatment decisions, it is important for healthcare providers to not only consider safety and efficacy, but also other treatment attributes that may affect patient preference.

Despite the existence of effective treatments, delays in treatment intensification are not uncommon in T2DM. ${ }^{14,15}$ Among patients with T2DM in KSA, researchers have documented an unwillingness to initiate treatment with insulin because of lifestyle restrictions, fear of hypoglycemia, and concerns about weight gain. ${ }^{16}$ While insulin is one treatment option available to address hyperglycemia, glucagon-like peptide-1 receptor agonists (GLP-1 RAs) are another alternative that have been shown to improve cardiovascular and renal outcomes, reduce hypoglycemia, and minimize weight gain. GLP-1 RAs are recommended as a treatment approach for T2DM when HbAlc levels exceed $7 \%$ and patients are overweight. ${ }^{10}$ Patient preference for the devices used to administer the GLP-1 RAs, dulaglutide and semaglutide, has been studied previously. For example, a significantly larger proportion of patients preferred the dulaglutide device $(84.2 \%)$ over the semaglutide device $(12.3 \%)$ in a cross-over trial of US patients with T2DM. ${ }^{17}$ Similar results were also found in a vignette-based study of these devices among Italian patients, with $88.4 \%$ preferring the dulaglutide device over the semaglutide device $(11.6 \%) .{ }^{18}$

There is limited research on T2DM patient characteristics, HRQoL, and treatment preferences among patients with diabetes in the Middle East, and specifically, in KSA. The aim of the current study was to begin to address this research gap. The purpose of the current study was to gather data on patients from this population to help better understand the characteristics, experiences, and challenges of patients with T2DM in KSA.

\section{Methods \\ Study Design}

A cross-sectional, observational study was conducted among patients with T2DM in KSA. The current study included three phases. In the first phase, 11 open-ended interviews were conducted to understand patient's current diabetes experience, including challenges of maintaining glycemic control and managing blood glucose levels during Ramadan. The qualitative results from this initial phase led to the development of a diabetes treatment survey, which was also informed by previous T2DM survey studies in the literature and expert feedback from T2DM researchers.

The survey was then piloted among 10 patients in the second phase of the study to assess participants' comprehension of the questions. Minor changes to questions were implemented based on qualitative feedback gathered in this phase. The third phase was a cross-sectional study in which a questionnaire including the final version of the diabetes treatment survey was administered to patients with T2DM between February and April 2019. Participants completed all questions on a laptop computer during an in-person session with a trained, same gender researcher. The surveys were completed at locations convenient to the participants in Jeddah, Riyadh, and Dammam (e.g., participants' houses, cafes, and/or public places).

\section{Study Sample}

Participants who were included in the study were KSA nationals between the ages of 30 and 75 who had received a T2DM diagnosis from a medical doctor and had no prior experience with self-injectable diabetes treatments. 
Participants with a cognitive disability, hearing difficulty, inability to be interviewed in person, type 1 or gestational diabetes diagnosis, and/or who were employed in the pharmaceutical industry (including family members) were excluded.

Participants were recruited from three cities (Jeddah, Riyadh, and Dammam) in KSA through patient panels, advertisements on social media, online forums, and diabetes organizations. Potential participants were invited via email or telephone to complete screening questions and were asked to provide documentation of a T2DM diagnosis (e.g., medical note, diabetes prescription). Interested and eligible participants received an invitation for an inperson interview; eligibility was confirmed before data collection commenced. Trained local researchers conducted the in-person interviews in Arabic. To ensure that procedures were appropriate for participants in the KSA, several cultural considerations/adaptations were implemented, including using interviewers who were the same gender as the participant, ensuring participants viewed videos containing figures of the same gender, and completing the study before Ramadan to minimize the impact on participation.

\section{Study Questionnaire}

The study questionnaire included four sections: 1) sociodemographic and clinical questions; 2) the EQ-5D-5L; 3) the Impact of Weight on Self-Perceptions (IW-SP) instrument; and 4) the diabetes treatment survey specifically developed for this study (see Supplemental material). The questionnaire was administered in Arabic.

Sociodemographic data were collected such as age, gender, ethnicity, marital status, employment status, education level, and household income. Clinical characteristics, including time since diagnosis, the type of healthcare professional who diagnosed the T2DM, HbA1c levels, and current treatments for T2DM, were also collected. The EQ-5D was used to assess health status with two sections: descriptive questions (mobility, self-care, usual activities, pain/discomfort, and anxiety/depression) and a visual analogue scale (VAS). ${ }^{19-22}$

The IW-SP is a three-item measure designed to assess self-perception in the context of one's weight among patients with T2DM and obesity. ${ }^{23}$ The measure includes three items that ask respondents about feeling unhappy with their physical appearance, feeling self-conscious in public, and feeling unhappy - all due to weight. The instrument is scored as the average of the item scores, which have a five-point scale ranging from "Always" to "Never," higher scores indicate better self-perception.

The diabetes treatment survey is comprised of 25 questions, including some with sub-questions (see Supplemental material). The survey was designed for this study and was intended to capture T2DM patients' beliefs regarding their diabetes condition, treatment experiences, willingness to use injectable medications, and challenges with maintaining glycemic control in KSA (ie, impacts of obesity and Ramadan on their condition). The diabetes treatment survey also evaluated patient preferences for the injection devices associated with two GLP-1 RAs: dulaglutide and semaglutide. Videos presented information on the two devices used to inject the medications based on manufacturers' instructions for use; one video illustrated device $\mathrm{X}$ (dulaglutide) and a second video showed device Y (semaglutide). Both videos were embedded into the survey and no product names were disclosed. Participants were assigned to watch videos that portrayed someone of the same gender to provide a culturally appropriate demonstration of self-injectable diabetes treatment. The content was the same for each genderspecific video. The order of the videos (device $\mathrm{X}$ versus $\mathrm{Y}$ ) was randomized across participants. After participants watched both videos, the participants completed the willingness to use and device preference questions.

Participants were required to provide written informed consent before completing study procedures, and all procedures and materials were approved by an independent institutional review board (Ethical \& Independent Review Services; Study Number: 18,205-01A approval date: 01/ 14/19). This study was conducted in accordance with the Declaration of Helsinki.

\section{Statistical Analyses}

Descriptive statistics were used to characterize the sample in terms of demographics, clinical characteristics, device preference, and patient-reported measures. Continuous variables were summarized with means and standard deviations and for categorical variables, frequencies and percentages were used.

The Prescott test and chi-squared test were performed to determine if a statistically significant difference in preferences for the two devices existed while taking into account device order (significance level at $\mathrm{p}<0.05$ ). ${ }^{24}$ The Prescott test accounted for potential "no preference" responses, whereas the chi-squared test compared responses when a preference was indicated. Descriptive preference results (frequencies and percentages) were also calculated. SAS ${ }^{\circledR}$ 
statistical software version 9.4 (SAS Institute Inc., Cary, NC) was used to conduct the statistical analyses.

\section{Results}

\section{Participant Sociodemographic Characteristics}

A total of 310 participants completed the study. The study sample had a mean age of 43 years old (standard deviation $[\mathrm{SD}]=8.7$ years), and slightly more than half $(53.2 \%)$ were male (Table 1). All participants in the study were Saudi nationals. Slightly more than half (56.1\%) of participants were employed at least part time (full-time $40.0 \%$; part-time $16.1 \%)$. Almost half (48.4\%) reported having a bachelor's degree, and another $44.2 \%$ with a secondary education as the highest degree. The most commonly reported annual household income revealed by a third of the sample (30.3\%) ranged between 200,000 and 399,999 SAR (equivalent to approximately $\$ 53,000-\$ 106,500$ USD).

\section{Self-Reported Clinical Information}

Participants' average mean time since diagnosis of T2DM was $6.3(\mathrm{SD}=5.0)$ years. A total of $49.4 \%$ of participants were diagnosed with T2DM by an internal medicine practitioner, and another $31.3 \%$ were diagnosed by a general practitioner (Table 2). The majority of participants selfreported that their last $\mathrm{HbA} 1 \mathrm{c}$ level was higher than $7 \%$, with 73 participants (23.5\%) reporting an HbAlc of $<7 \%$, 139 participants $(44.8 \%)$ reporting a range between $7.1 \%$ and $8 \%, 60$ participants (19.4\%) reporting a range between $8.1 \%$ and $9 \%$, and 28 participants $(9.0 \%)$ reporting a range of $9 \%$ or higher. The self-reported mean body mass index of the study sample was $29.5(\mathrm{SD}=5.7)$.

Most participants reported that their T2DM was treated with medication (88.7\%) and/or diet (65.2\%). Among those who reported taking medication, oral medication monotherapy was reported by $50.0 \%$ of participants. Additionally, participants reported seeing a healthcare professional on average 6.8 times $(\mathrm{SD}=3.7)$ a year for T2DM management.

\section{Impact of T2DM \\ Overall Impact}

Overall, $77.1 \%$ of participants reported at least some level of impact when asked "How much impact does your T2DM have on your life?" (some [52.6\%], moderate [21.9\%], and severe [2.6\%]). Participants cited a variety of specific impacts, including: eating behavior (e.g., food choices, relationship with food, timing of eating) $(49.7 \%)$, leisure activities (33.2\%), and emotions (32.9\%). Further, over $78.7 \%$ of participants reported that they "worried about their diabetes" ("A little" $=46.1 \%$; "A moderate amount" $=24.5 \%$; or "A great deal" $=8.1 \%$ ).

\section{Impact During Ramadan}

Approximately one-fifth of the participants (20.0\%) reported being unable to fast for an average of seven days $(\mathrm{SD}=4.4)$ during Ramadan because of their diabetes (Table 3). Females were significantly more likely to report being unable to fast compared to males ( $\mathrm{p}<0.0044$ ). However, a greater proportion of males reported worrying about their condition when they fasted during Ramadan ( $\mathrm{p}<0.05)$. In addition, older participants were more likely to report that fasting during Ramadan made them worry about their T2DM ( $\mathrm{p}=0.0004)$. When asked what steps they took to prepare for fasting during Ramadan, participants were most likely to report talking with their physician or healthcare team (37.1\%), checking blood glucose levels more than normal (37.1\%), and/or reducing or limiting activity (29.7\%).

\section{Impact of Weight}

A total of 121 participants (39.0\%) reported impacts in response to a general question about whether their weight impacts their day-to-day activities. The most commonly reported areas of impact were leisure activities (62.0\%) and housekeeping (36.4\%), but participants also reported impacts on self-care (22.3\%), social activities (20.7\%), work (19.8\%), and family (16.5\%).

In addition to impacts on daily activities due to weight, participants also reported some negative impacts on their selfperception. On the IW-SP, approximately $28.9 \%$ (sometimes: $23.5 \%$, frequently: $4.8 \%$, and always: $0.6 \%$ ) of participants felt unhappy with their appearance because of their weight, an estimated $26.5 \%$ (sometimes: $19.4 \%$, frequently: $6.1 \%$, and always: $1.0 \%$ ) felt that when comparing themselves with others they were unhappy due to their weight, and about $22.0 \%$ felt self-conscious when going out in public (sometimes: $18.7 \%$, frequently: $2.3 \%$, and always: $1.0 \%$ ). The mean raw score on the IW-SP was 4.1 ( $\mathrm{SD}=0.9$; range $1-5$ ), indicating a low to moderate impact of weight on selfperception overall. There were significant age and gender trends with older participants and females reporting the greatest impact of weight on self-perception (both $\mathrm{p}<0.05$ ).

\section{Health-Related Quality of Life}

Results from the EQ-5D-5L were used to evaluate the overall health of the sample. The mean EQ-5D-5L index score was 0.90 ( $\mathrm{SD}=0.14$; range: $-0.09-1.00$ ). The mean VAS 
Table I Demographic Characteristics

\begin{tabular}{|c|c|c|c|c|c|c|c|c|}
\hline & \multirow{2}{*}{$\begin{array}{l}\text { Total } \\
(\mathrm{N}=3 \mid 0)\end{array}$} & \multicolumn{4}{|l|}{ Age } & \multicolumn{3}{|l|}{ Gender } \\
\hline & & $\begin{array}{l}<40 \text { Years } \\
(n=|| 7)\end{array}$ & $\begin{array}{l}40-50 \text { Years } \\
(n=136)\end{array}$ & $\begin{array}{l}50+\text { Years } \\
(n=57)\end{array}$ & $p$-value ${ }^{c}$ & $\begin{array}{l}\text { Male } \\
(n=165)\end{array}$ & $\begin{array}{l}\text { Female } \\
(n=\mid 45)\end{array}$ & $p_{\text {-value }}{ }^{d}$ \\
\hline \multicolumn{9}{|l|}{ Ethnicity, n (\%) } \\
\hline $\begin{array}{l}\text { Saudi Arab } \\
\text { Yemeni } \\
\text { Other }^{\mathrm{a}}\end{array}$ & $\begin{array}{l}305(98.4 \%) \\
3(1.0 \%) \\
2(0.6 \%)\end{array}$ & $\begin{array}{l}117(100.0 \%) \\
0(0.0 \%) \\
0(0.0 \%)\end{array}$ & $\begin{array}{l}133(97.8 \%) \\
2(1.5 \%) \\
\text { I }(0.7 \%)\end{array}$ & $\begin{array}{l}55(96.5 \%) \\
\text { I (I.8\%) } \\
\text { I (I.8\%) }\end{array}$ & 0.4384 & $\begin{array}{l}160(97.0 \%) \\
3(1.8 \%) \\
2(1.2 \%)\end{array}$ & $\begin{array}{l}145(100.0 \%) \\
0(0.0 \%) \\
0(0.0 \%)\end{array}$ & 0.1072 \\
\hline \multicolumn{9}{|l|}{ Marital status, n (\%) } \\
\hline $\begin{array}{l}\text { Single } \\
\text { Married } \\
\text { Divorced } \\
\text { Widowed }\end{array}$ & $\begin{array}{l}48(15.5 \%) \\
256(82.6 \%) \\
2(0.6 \%) \\
4(1.3 \%)\end{array}$ & $\begin{array}{l}3 \mathrm{I}(26.5 \%) \\
84(71.8 \%) \\
\text { I (0.9\%) } \\
\text { I (0.9\%) }\end{array}$ & $\begin{array}{l}\text { II ( } 8.1 \%) \\
\text { I24 (9I.2\%) } \\
\text { I (0.7\%) } \\
0(0.0 \%)\end{array}$ & $\begin{array}{l}6(10.5 \%) \\
48(84.2 \%) \\
0(0.0 \%) \\
3(5.3 \%)\end{array}$ & 0.0001 & $\begin{array}{l}46(27.9 \%) \\
\text { II (71.5\%) } \\
\text { I (0.6\%) } \\
0(0.0 \%)\end{array}$ & $\begin{array}{l}2(1.4 \%) \\
\text { I } 38(95.2 \%) \\
\text { I }(0.7 \%) \\
4(2.8 \%)\end{array}$ & $<0.0001$ \\
\hline \multicolumn{9}{|l|}{ Employment status, n (\%) } \\
\hline $\begin{array}{l}\text { Full-time work } \\
\text { Part-time work } \\
\text { Homemaker/housewife } \\
\text { Student } \\
\text { Unemployed } \\
\text { Retired } \\
\text { Other }\end{array}$ & $\begin{array}{l}124(40.0 \%) \\
50(16.1 \%) \\
119(38.4 \%) \\
0(0.0 \%) \\
8(2.6 \%) \\
9(2.9 \%) \\
0(0.0 \%)\end{array}$ & $\begin{array}{l}47(40.2 \%) \\
21(17.9 \%) \\
45(38.5 \%) \\
0(0.0 \%) \\
4(3.4 \%) \\
0(0.0 \%) \\
0(0.0 \%)\end{array}$ & $\begin{array}{l}56(41.2 \%) \\
23(16.9 \%) \\
53(39.0 \%) \\
0(0.0 \%) \\
1(0.7 \%) \\
3(2.2 \%) \\
0(0.0 \%)\end{array}$ & $\begin{array}{l}21(36.8 \%) \\
6(10.5 \%) \\
21(36.8 \%) \\
0(0.0 \%) \\
3(5.3 \%) \\
6(10.5 \%) \\
0(0.0 \%)\end{array}$ & 0.0090 & $\begin{array}{l}109(66.1 \%) \\
45(27.3 \%) \\
0(0.0 \%) \\
0(0.0 \%) \\
2(1.2 \%) \\
9(5.5 \%) \\
0(0.0 \%)\end{array}$ & $\begin{array}{l}15(10.3 \%) \\
5(3.4 \%) \\
119(82.1 \%) \\
0(0.0 \%) \\
6(4.1 \%) \\
0(0.0 \%) \\
0(0.0 \%)\end{array}$ & $<0.0001$ \\
\hline \multicolumn{9}{|c|}{ Highest level of education, $\mathbf{n}(\%)$} \\
\hline $\begin{array}{l}\text { Primary School } \\
\text { Intermediate Education } \\
\text { Secondary Education } \\
\text { University degree (BA, BSc) } \\
\text { Post-graduate degree (MA, } \\
\text { PhD, PGCE) } \\
\text { Other }\end{array}$ & $\begin{array}{l}3(1.0 \%) \\
8(2.6 \%) \\
137(44.2 \%) \\
150(48.4 \%) \\
10(3.2 \%) \\
2(0.6 \%)\end{array}$ & $\begin{array}{l}\text { I }(0.9 \%) \\
\text { I }(0.9 \%) \\
48(41.0 \%) \\
63(53.8 \%) \\
4(3.4 \%) \\
0(0.0 \%)\end{array}$ & $\begin{array}{l}\text { I }(0.7 \%) \\
6(4.4 \%) \\
57(41.9 \%) \\
65(47.8 \%) \\
6(4.4 \%) \\
\text { I (0.7\%) }\end{array}$ & $\begin{array}{l}\text { I (1.8\%) } \\
\text { I (1.8\%) } \\
32(56.1 \%) \\
22(38.6 \%) \\
0(0.0 \%) \\
\text { I (1.8\%) }\end{array}$ & 0.2748 & $\begin{array}{l}\text { I }(0.6 \%) \\
6(3.6 \%) \\
66(40.0 \%) \\
88(53.3 \%) \\
3(1.8 \%) \\
I(0.6 \%)\end{array}$ & $\begin{array}{l}2(1.4 \%) \\
2(1.4 \%) \\
71(49.0 \%) \\
62(42.8 \%) \\
7(4.8 \%) \\
1(0.7 \%)\end{array}$ & 0.1950 \\
\hline \multicolumn{9}{|c|}{ Total household income in last 12 months, $n$ (\%) } \\
\hline $\begin{array}{l}25,999 \text { SAR or less } \\
26,000 \text { to } 199,999 \text { SAR } \\
200,000 \text { to } 399,999 \text { SAR } \\
400,000 \text { to } 599,999 \text { SAR } \\
600,000 \text { to } 799,999 \text { SAR } \\
800,000 \text { or more SAR } \\
\text { Prefer not to answer }\end{array}$ & $\begin{array}{l}12(3.9 \%) \\
87(28.1 \%) \\
94(30.3 \%) \\
52(16.8 \%) \\
26(8.4 \%) \\
8(2.6 \%) \\
31(10.0 \%)\end{array}$ & $\begin{array}{l}7(6.0 \%) \\
31(26.5 \%) \\
37(31.6 \%) \\
17(14.5 \%) \\
10(8.5 \%) \\
4(3.4 \%) \\
11(9.4 \%)\end{array}$ & $\begin{array}{l}3(2.2 \%) \\
37(27.2 \%) \\
44(32.4 \%) \\
20(14.7 \%) \\
12(8.8 \%) \\
4(2.9 \%) \\
16(11.8 \%)\end{array}$ & $\begin{array}{l}2(3.5 \%) \\
19(33.3 \%) \\
13(22.8 \%) \\
15(26.3 \%) \\
4(7.0 \%) \\
0(0.0 \%) \\
4(7.0 \%)\end{array}$ & 0.5170 & $\begin{array}{l}11(6.7 \%) \\
56(33.9 \%) \\
36(21.8 \%) \\
29(17.6 \%) \\
17(10.3 \%) \\
4(2.4 \%) \\
12(7.3 \%)\end{array}$ & $\begin{array}{l}\text { I }(0.7 \%) \\
31(21.4 \%) \\
58(40.0 \%) \\
23(15.9 \%) \\
9(6.2 \%) \\
4(2.8 \%) \\
19(13.1 \%)\end{array}$ & 0.0005 \\
\hline
\end{tabular}

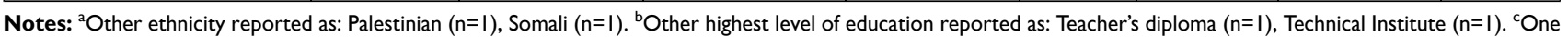
way analyses of variance overall F statistic $p$-value for continuous variables and $\chi^{2}$ test $p$-value for categorical variables by age group. Independent samples $t$-test $p$-value for continuous variables and $\chi^{2}$ test $p$-value for categorical variables by gender.

score was $80(\mathrm{SD}=13$; range $41-100)$. At least some problems with pain (34.5\%) and usual activities (33.2\%) were reported (Figure 1); the majority reported no problems on the other domains. There were significant gender and age differences for all EQ-5D dimensions and for both the index and VAS scores; younger participants and females consistently reported significantly better health (all $\mathrm{p}<0.05$ ).

\section{Injection Willingness and Device Preference}

Initially, almost a third $(28.0 \%)$ of participants were "somewhat willing" or "very willing" to take a diabetes medication that required an injection for each dose. After watching the videos that described the injection process for two GLP-1 RA agents, participants' willingness to inject increased and was significantly higher for device 


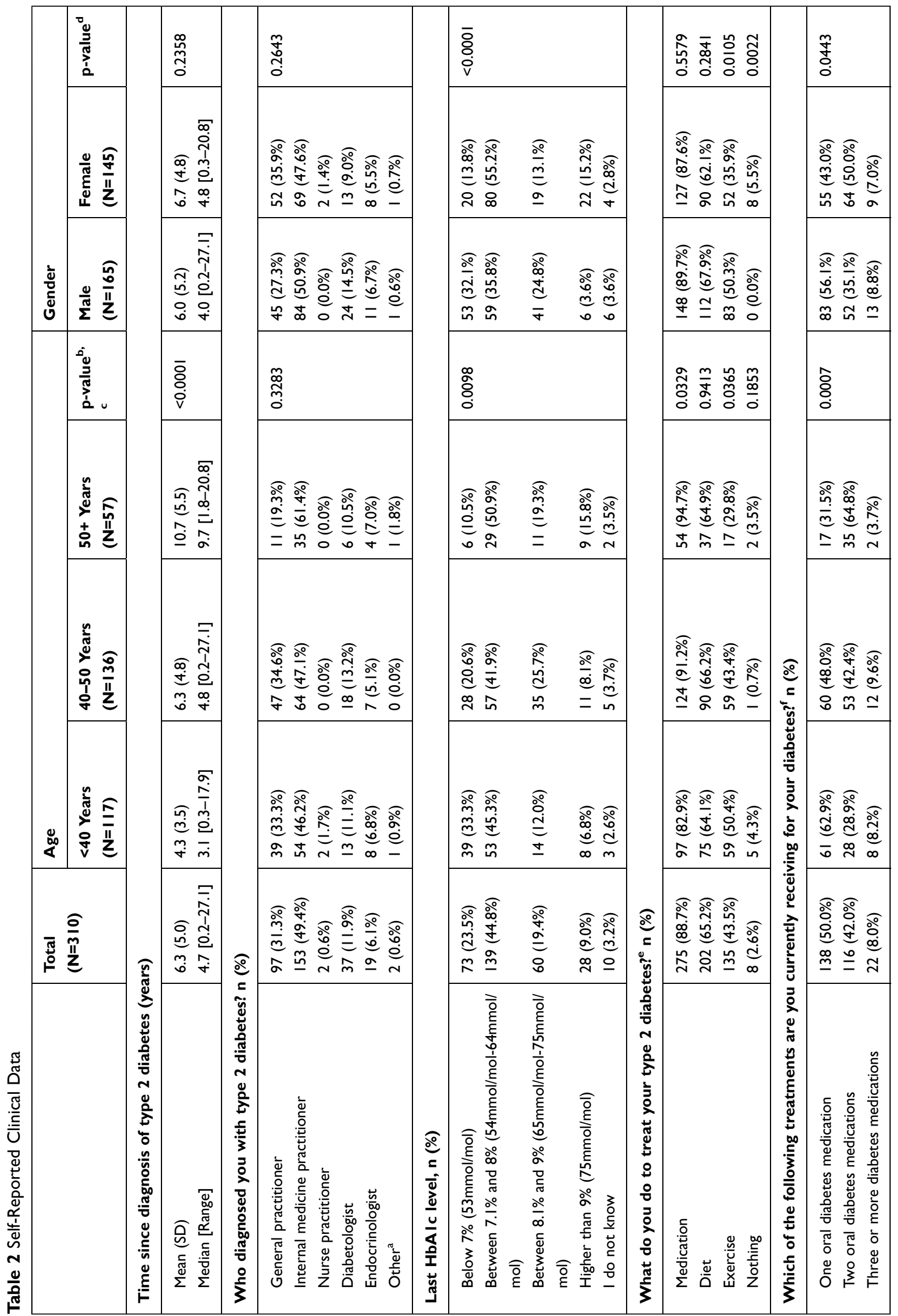


$\mathrm{X}$ (dulaglutide; 47.4\%) compared to device $\mathrm{Y}$ (semaglutide; 32.5\%) $(\mathrm{p}<0.0001$; Figure 2).

Most participants $\quad(n=277 ; 89.4 \%) \quad$ indicated a preference for one of the two devices highlighted in the videos. Of those indicating a preference, at least twice as many participants preferred the dulaglutide device $(\mathrm{n}=186,67.1 \%)$ over the semaglutide device $(\mathrm{n}=91$, $32.9 \% ; p<0.0001)$. The most common reasons for this preference included the device looked easy to use (46.2\%), device design (15.2\%), device needle (13.4\%), and the number of doses in the device (13.4\%).

\section{Discussion}

In this cross-sectional study conducted in Saudi Arabia, we sought to understand patients' perspectives and experiences with T2DM, including treatments and impacts. Given that few studies have been conducted on T2DM in KSA to date, the findings provide some key insights. First, the majority of the participants managed their condition with oral medications $(88.7 \%)$ and/or diet $(65.2 \%)$. However, the current treatments may not be effective for many of these patients, as indicated by self-reported recent HbAlc levels over $7 \%$ in the majority (73.2\%) of the participants. Previous studies in KSA suggest that treatment adherence could interfere with treatment effectiveness. For example, in a large retrospective study $(\mathrm{n}=5457)$ conducted in a tertiary hospital in KSA, it was reported that only $49 \%$ of T2DM patients demonstrated good adherence when taking oral medications. ${ }^{25}$ In another study conducted by Alyami et al in KSA, only two-thirds (69\%) of the adult participants reported good adherence to medication. $^{26}$

Based on the EQ-5D-5L, the participants in the current study were relatively healthy in terms of mobility, selfcare, and anxiety/depression. However, approximately one-third of the participants reported at least some problems with pain and discomfort and/or usual care. Further research might be useful to better understand if selfreported pain levels are related to neuropathy, arthritis, or other co-morbidities. Interestingly, the IW-SP self-reported responses indicated a low impact of weight on selfperception in the KSA sample. To our knowledge, no previous studies have utilized the IW-SP in studies within KSA.

The majority (78.7\%) of participants were worried about their T2DM and reported impacts across a wide range of domains including eating behaviors, leisure activities, and emotions. Given the paucity of diabetes research in KSA, 
Table 3 Fasting Behaviors During Ramadan

\begin{tabular}{|c|c|c|c|c|c|c|c|c|}
\hline & \multirow{2}{*}{$\begin{array}{l}\text { Total } \\
(\mathrm{N}=3 \mid 0)\end{array}$} & \multicolumn{4}{|l|}{ Age } & \multicolumn{3}{|l|}{ Gender } \\
\hline & & $\begin{array}{l}<40 \text { Years } \\
(N=|| 7)\end{array}$ & $\begin{array}{l}40-50 \\
\text { Years } \\
(N=136)\end{array}$ & $\begin{array}{l}50+\text { Years } \\
(\mathrm{N}=57)\end{array}$ & p-value ${ }^{c}$ & $\begin{array}{l}\text { Male } \\
(\mathrm{N}=165)\end{array}$ & $\begin{array}{l}\text { Female } \\
(\mathrm{N}=145)\end{array}$ & p-value ${ }^{d}$ \\
\hline \multicolumn{9}{|c|}{ Were there any days you were not able to fast from dawn to sundown during the last Ramadan (2018)? n, (\%) } \\
\hline Yes & $62(20.0 \%)$ & $15(12.8 \%)$ & $29(21.3 \%)$ & $18(31.6 \%)$ & 0.0129 & $23(13.9 \%)$ & $39(26.9 \%)$ & 0.0044 \\
\hline No & $248(80.0 \%)$ & $102(87.2 \%)$ & $107(78.7 \%)$ & $39(68.4 \%)$ & & $142(86.1 \%)$ & $106(73.1 \%)$ & \\
\hline \multicolumn{9}{|c|}{ Approximately how many days were you unable to fast during the last Ramadan $(2018) ?^{a}$} \\
\hline Mean (SD) & $7.0(4.4)$ & $7.1(4.3)$ & $7.2(4.2)$ & $6.7(4.9)$ & 0.9244 & $3.4(1.6)$ & $9.2(4.1)$ & $<0.0001$ \\
\hline Median [Range] & $\begin{array}{l}6.0 \\
{[1.0-15.0]}\end{array}$ & $\begin{array}{l}6.0 \\
{[1.0-15.0]}\end{array}$ & $\begin{array}{l}7.0 \\
{[1.0-15.0]}\end{array}$ & $\begin{array}{l}5.0 \\
{[1.0-15.0]}\end{array}$ & & $\begin{array}{l}3.0 \\
{[1.0-6.0]}\end{array}$ & $\begin{array}{l}10.0 \\
{[1.0-15.0]}\end{array}$ & \\
\hline \multicolumn{9}{|c|}{ Does fasting during Ramadan make you worry about your type 2 diabetes? $n,(\%)^{a}$} \\
\hline Yes & $100(32.3 \%)$ & $23(19.7 \%)$ & $50(36.8 \%)$ & $27(47.4 \%)$ & 0.0004 & $62(37.6 \%)$ & $38(26.2 \%)$ & 0.0326 \\
\hline No & $210(67.7 \%)$ & $94(80.3 \%)$ & $86(63.2 \%)$ & $30(52.6 \%)$ & & $103(62.4 \%)$ & $107(73.8 \%)$ & \\
\hline \multicolumn{9}{|c|}{ What steps do you take to prepare, if any, for your type 2 diabetes during Ramadan? n, (\%) } \\
\hline $\begin{array}{l}\text { I talk to my physician and/or } \\
\text { healthcare team about strategies for } \\
\text { managing diabetes while fasting }\end{array}$ & $115(37.1 \%)$ & $41(35.0 \%)$ & $52(38.2 \%)$ & $22(38.6 \%)$ & 0.8428 & $75(45.5 \%)$ & $40(27.6 \%)$ & 0.0012 \\
\hline $\begin{array}{l}\text { Before starting the fast, I eat more } \\
\text { food than I usually do }\end{array}$ & $47(15.2 \%)$ & $13(11.1 \%)$ & $25(18.4 \%)$ & $9(15.8 \%)$ & 0.2716 & $14(8.5 \%)$ & $33(22.8 \%)$ & 0.0005 \\
\hline $\begin{array}{l}\text { Before starting the fast, I eat different } \\
\text { foods }\end{array}$ & $51(16.5 \%)$ & $19(16.2 \%)$ & $22(16.2 \%)$ & $10(17.5 \%)$ & 0.9701 & $21(12.7 \%)$ & $30(20.7 \%)$ & 0.0592 \\
\hline $\begin{array}{l}\text { I check my blood glucose levels more } \\
\text { often than normal }\end{array}$ & 115 (37.1\%) & $32(27.4 \%)$ & 57 (4I.9\%) & $26(45.6 \%)$ & 0.0194 & $68(41.2 \%)$ & 47 (32.4\%) & 0.1096 \\
\hline $\begin{array}{l}\text { I change my medication dose prior to } \\
\text { Ramadan }\end{array}$ & $62(20.0 \%)$ & $24(20.5 \%)$ & $28(20.6 \%)$ & $10(17.5 \%)$ & 0.8765 & $16(9.7 \%)$ & $46(31.7 \%)$ & $<0.0001$ \\
\hline $\begin{array}{l}\text { I change my medication dose during } \\
\text { Ramadan }\end{array}$ & $65(21.0 \%)$ & $24(20.5 \%)$ & $30(22.1 \%)$ & II (19.3\%) & 0.9011 & $33(20.0 \%)$ & $32(22.1 \%)$ & 0.6552 \\
\hline $\begin{array}{l}\text { I take medication at a different time } \\
\text { of day }\end{array}$ & 91 (29.4\%) & $28(23.9 \%)$ & $46(33.8 \%)$ & $17(29.8 \%)$ & 0.2259 & 48 (29.1\%) & $43(29.7 \%)$ & 0.9133 \\
\hline $\begin{array}{l}\text { I change my medication to prepare } \\
\text { for Ramadan }\end{array}$ & $52(17.3 \%)$ & $23(20.2 \%)$ & $24(18.3 \%)$ & $5(9.1 \%)$ & 0.1883 & $12(7.6 \%)$ & $40(28.2 \%)$ & $<0.0001$ \\
\hline Reduce or limit activity & $92(29.7 \%)$ & 31 (26.5\%) & $40(29.4 \%)$ & $21(36.8 \%)$ & 0.3727 & 55 (33.3\%) & 37 (25.5\%) & 0.1328 \\
\hline I do not take any specific steps & $45(14.5 \%)$ & $22(18.8 \%)$ & $16(11.8 \%)$ & 7 (12.3\%) & 0.2475 & 30 (18.2\%) & $15(10.3 \%)$ & 0.0506 \\
\hline I do not know & $4(1.3 \%)$ & I (0.9\%) & $2(1.5 \%)$ & $\mathrm{I}(1.8 \%)$ & 0.8584 & $3(1.8 \%)$ & I (0.7\%) & 0.3797 \\
\hline
\end{tabular}

Notes: ${ }^{\mathrm{a}}$ articipants completed only if indicating they were unable to fast during the last Ramadan. ${ }^{\mathrm{b}}$ Responses not mutually exclusive. ${ }^{\mathrm{c}}$ One way analyses of variance overall $\mathrm{F}$ statistic $\mathrm{p}$-value for continuous variables and $\chi^{2}$ test $\mathrm{p}$-value for categorical variables by age group. Independent samples $t$-test $\mathrm{p}$-value for continuous variables and $\chi^{2}$ test $\mathrm{P}$-value for categorical variables by gender.

little was previously known about the impacts of T2DM from the patient perspective in this region. However, study findings from other countries indicate comparable negative psychosocial effects, such as depression, anxiety, and work challenges. ${ }^{27,28}$ These broad and pervasive impacts appear to also be issues for patients in KSA.

Fasting behavior during Ramadan was studied to gauge the impact on T2DM patients. Ensuring appropriate care for T2DM patients who fast during Ramadan is vital, ${ }^{29}$ and is more likely to be achieved with a better understanding of patients' experiences during this annual observance. Among the $20 \%$ of participants who reported being unable to fast throughout the duration of Ramadan, the average number of days missed was around 7. This finding is consistent with International Diabetes Federation (IDF) guidelines for diabetic patients fasting during Ramadan. ${ }^{29}$ A prior study in Morocco reported comparable findings; diabetic patients fasted for approximately 23 out of 30 days, ${ }^{30}$ while in Tunisia only $72 \%$ of T2DM patients fasted without interruption during the month of 


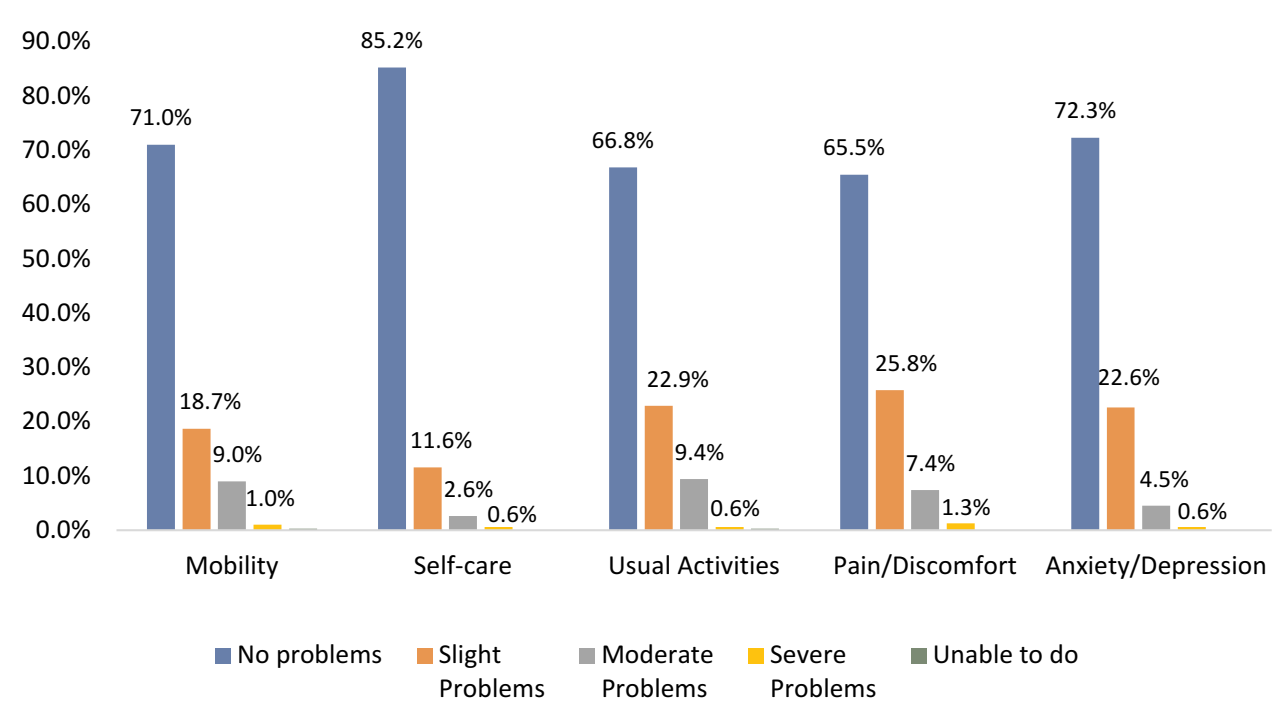

Figure I EQ-5D-5L dimension scores $(\mathrm{N}=310)$.

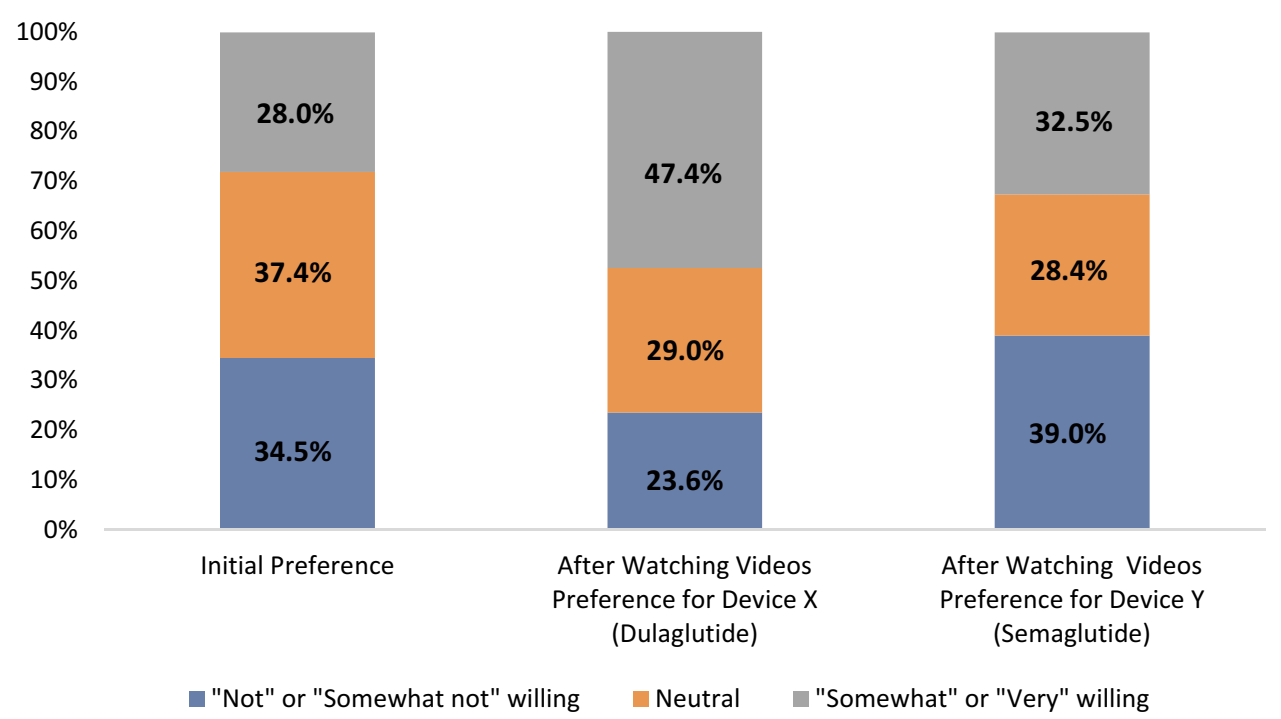

Figure 2 Willingness to use injectable diabetes medications.

Ramadan. ${ }^{31}$ In a recent multi-country, retrospective, observational study collecting data before, during, and after Ramadan, Jabbar et al reported that patients in the Middle East have the greatest number of days of fasting for people on oral anti-diabetic medications (average of 28.8 days) compared to Asia, North Africa, and Europe. ${ }^{32}$ In the current study, about a quarter $(26.9 \%)$ of females reported not being able to fast during Ramadan compared to $13.9 \%$ of males. However, males reported worrying more about their condition during Ramadan $37.6 \%$ for males versus $26.2 \%$ for females). Other studies report mixed results related to gender and fasting behavior. While one study did not report any gender differences in fasting, ${ }^{30}$ others have found that males were more likely to participate in no-interruption fasting compared to females in Tunisia. ${ }^{31}$ Gender differences related to fasting during Ramadan merit further research to better understand the sociocultural factors that may be relevant.

The findings of the current study provide further support for positive attitudes toward self-injectable diabetes treatments, in particular once patients are provided with information about the use of the devices. In the current 
study, while only $28 \%$ of participants were willing to use an injectable medication prior to watching the videos, participants were more willing to use the injectable medications after watching the product videos. In particular, they were more likely to be willing to inject using the dulaglutide device (47.4\%) compared to the semaglutide device (32.5\%). This is consistent with the results of other studies conducted in Japan and the UK, ${ }^{33,34}$ which found that patients were more willing to use injectable treatments after learning specific information about the products. Interestingly, in the present study, the proportion of patients who were unwilling to use the semaglutide device was higher after patients learned about the injection devices (39.0\%) compared with the $34.5 \%$ who were unwilling to use an injectable medication initially. In prior studies, significantly more patients preferred the dulaglutide profile compared to the liraglutide profile primarily because of non-clinical factors such as convenience and ease of use. In Japan, 95\% of patients preferred the dulaglutide profile over that of liraglutide $(6 \%)$, and $83 \%$ of patients in the UK preferred the dulaglutide profile compared to the liraglutide profile (17\%). The EASD guidelines recommend that treatment plans be developed in conjunction with patient preferences. ${ }^{10}$ Understanding patients' preferences may facilitate better patient-provider conversations and clinical decision-making, potentially resulting in better clinical and economic outcomes.

Certain cultural considerations were paramount to conducting research in KSA. Given that Arab countries generally value social connections, even in business situations, establishing face-to-face rapport and training local staff in Arabic was essential to the success of the study. Utilizing separate gender-based videos to comply with cultural norms was also important to best engage research participants. Lastly, people were less available during the month of Ramadan and it is advisable to avoid recruitment during this time.

The results should be considered in the context of a few limitations. Because recruitment was conducted using patient panels, the sample may not be fully representative of the T2DM population in KSA. In addition, the patient population was slightly younger than expected, which may be related to the recruitment methods. ${ }^{35}$ The survey was a combination of existing measures and additional diabetes and treatment questions developed to achieve the objectives of this study; the measurement properties of these additional questions are not known though the questions were clear, straight-forward, pre-tested, and qualitatively debriefed in a small subsample of the respondents. Lastly, this study was designed to capture preference data on two specific GLP-1 RA devices (ie, for dulaglutide and semaglutide), and therefore, the results do not provide insight into patient preferences for other injection devices in the GLP-1 RA or other medication classes. Additional research is recommended to highlight patient preferences given the rising rates of diabetes in KSA and the Middle East. The results of this study suggest that patients are more willing to use injectable diabetes treatments after they find out more information and to use injectable devices that they perceive as easy to use.

The results of this study suggest that T2DM has a significant social, emotional, and behavioral impact on the lives of patients in KSA. The study provides interesting insights on fasting behavior during Ramadan in this population and provides new data on the willingness of patients to use injectable GLP-1 RA treatments and their preferences for specific injection devices in KSA. These insights may be helpful to healthcare providers who care for patients with T2DM in KSA.

\section{Abbreviations}

EASD, European Association for the Study of Diabetes; GLP-1 RA, glucagon-like peptide-1 receptor agonist; HRQoL, health-related quality of life; IDF, International Diabetes Federation; IW-SP, Impact of Weight on SelfPerceptions; KSA, Kingdom of Saudi Arabia; T2DM, Type 2 diabetes mellitus; VAS, visual analogue scale.

\section{Data Sharing Statement}

Participants did not provide consent to share individual data, data are kept on file by the investigators.

\section{Ethics Approval and Informed Consent}

Participants were required to provide written informed consent before completing study procedures, and all procedures and materials were approved by an independent institutional review board (Ethical \& Independent Review Services; Study Number: 18,205-01A approval date: 01/14/19). This study was conducted in accordance with the Declaration of Helsinki.

\section{Acknowledgments}

The authors thank the patients and staff who participated in this study. 


\section{Author Contributions}

All authors made a significant contribution to the work reported, and all collaborated on the study design, analysis plan, interpretation of data, and outline of the manuscript. The co-authors HG, HS, LM, JJ, and SA drafted the manuscript text, and the co-authors $\mathrm{KB}, \mathrm{AA}, \mathrm{AE}$, and AS critically reviewed the article. All authors have agreed on the submission to this journal and have reviewed and agreed on all versions of the article. All authors agree to take responsibility and be accountable for the contents of the article.

\section{Funding}

The study was funded by Eli Lilly and Company.

\section{Disclosure}

Heather L. Gelhorn, Louis S. Matza, Jessica B. Jordan, Savita B. Anand, and Huda Shalhoub are employees of Evidera, a company that received funding from Eli Lilly for time spent conducting this research. Alena A. Strizek, Kristina S. Boye, and Ali Alhammad are employees of and own stock in Eli Lilly and Company. Dr. Aishah A. Ekhzaimy is not an employee of Eli Lilly and Company and has no conflict of interest to disclose. The authors report no other potential conflicts of interest for this work.

\section{References}

1. Kaiser AB, Zhang N, Van Der Pluijm W. Global prevalence of type 2 diabetes over the next ten years (2018-2028). Poster \#202-LB. Poster presented at the: American Diabetes Association; 2018:67.

2. Al Dawish MA, Robert AA, Braham R, et al. Diabetes mellitus in saudi arabia: a review of the recent literature. Curr Diabetes Rev. 2016;12(4):359-368. doi:10.2174/1573399811666150724095130

3. Meo SA. Prevalence and future prediction of type 2 diabetes mellitus in the Kingdom of Saudi Arabia: a systematic review of published studies. J Pak Med Assoc. 2016;66(6):722-725.

4. Al Slail FY, Abid O, Assiri AM, Memish ZA, Ali MK. Cardiovascular risk profiles of adults with type-2 diabetes treated at urban hospitals in Riyadh, Saudi Arabia. J Epidemiol Glob Health. 2016;6(1):29-36. doi:10.1016/j.jegh.2015.07.004

5. IMS Institute for Healthcare Informatics. Improving Type 2 Diabetes Therapy Compliance and Persistence in the Kingdom of Saudi Arabia. Parsippany, NJ; 2016.

6. Alzaheb RA, Altemani AH. The prevalence and determinants of poor glycemic control among adults with type 2 diabetes mellitus in Saudi Arabia. Diabetes Metab Syndr Obes. 2018;11:15-21. doi:10.2147/ DMSO.S156214

7. Gordon J, McEwan P, Idris I, Evans M, Puelles J. Treatment choice, medication adherence and glycemic efficacy in people with type 2 diabetes: a UK clinical practice database study. BMJ Open Diabetes Res Care. 2018;6(1):e000512. doi:10.1136/bmjdrc-2018-000512

8. Khayyat SM, Mohamed MMA, Khayyat SMS, et al. Association between medication adherence and quality of life of patients with diabetes and hypertension attending primary care clinics: a cross-sectional survey. Qual Life Res. 2019;28(4):1053-1061. doi:10.1007/s11136-018-2060-8
9. Buse JB, Wexler DJ, Tsapas A, et al. 2019 Update to: management of Hyperglycemia in Type 2 Diabetes, 2018. A Consensus Report by the American Diabetes Association (ADA) and the European Association for the Study of Diabetes (EASD). Diabetes Care. 2020;43 (2):487-493. doi:10.2337/dci19-0066

10. Davies MJ, D'Alessio DA, Fradkin J, et al. Management of hyperglycaemia in type 2 diabetes, 2018. A consensus report by the American Diabetes Association (ADA) and the European Association for the Study of Diabetes (EASD). Diabetologia. 2018;61(12):2461-2498.

11. Schaller M, Sigurgeirsson B, Sarkany M. Patient-reported outcomes from two randomised studies comparing once-weekly application of amorolfine 5\% nail lacquer to other methods of topical treatment in distal and lateral subungual onychomycosis. Mycoses. 2017;60 (12):800-807. doi:10.1111/myc.12676

12. Shikiar R, Rentz AM. Satisfaction with medication: an overview of conceptual, methodologic, and regulatory issues. Value Health. 2004;7(2):204-215. doi:10.1111/j.1524-4733.2004.72252.x

13. Shingler SL, Bennett BM, Cramer JA, Towse A, Twelves C, Lloyd AJ. Treatment preference, adherence and outcomes in patients with cancer: literature review and development of a theoretical model. Curr Med Res Opin. 2014;30(11):2329-2341. doi:10.1185/ 03007995.2014.952715

14. Boye KS, Stein D, Matza LS, et al. Timing of GLP-1 receptor agonist initiation for treatment of type 2 diabetes in the UK. Drugs $R D$. 2019;19(2):213-225. doi:10.1007/s40268-019-0273-0

15. Okemah J, Peng J, Quinones M. Addressing clinical inertia in type 2 diabetes mellitus: a review. Adv Ther. 2018;35(11):1735-1745. doi:10.1007/s12325-018-0819-5

16. Batais MA, Schantter P. Prevalence of unwillingness to use insulin therapy and its associated attitudes amongst patients with type 2 diabetes in Saudi Arabia. Prim Care Diabetes. 2016;10(6):415-424. doi:10.1016/j.pcd.2016.05.007

17. Matza LS, Boye KS, Stewart KD, et al. Assessing patient PREFERence between the dulaglutide pen and the semaglutide pen: a crossover study (PREFER). Diabetes Obes Metab. 2020;22 (3):355-364

18. Boye KS, Matza LS, Stewart KD, et al. Patient preferences and health state utilities associated with dulaglutide and semaglutide injection devices among patients with type 2 diabetes in Italy. $J$ Med Econ. 2019;22(8):806-813. doi:10.1080/13696998.2019.1609482

19. Brooks R. EuroQol: the current state of play. Health Policy (New York). 1996;37(1):53-72. doi:10.1016/0168-8510(96)00822-6

20. EuroQol Group. EuroQol a new facility for the measurement of health related quality of life. Health Policy (New York). 1990;16 (3):199-208. doi:10.1016/0168-8510(90)90421-9

21. Kind P. The EuroQol Instrument: an index of health related quality of life. In: Spilker B, editor. Quality of Life and Pharmacoeconomics in Clinical Trials. 2nd ed. Philadelphia, Pennsylvania: Lippincott Raven Publishers; 1996:191-201.

22. Rabin R, Gudex C, Selai C, Herdman M. From translation to version management: a history and review of methods for the cultural adaptation of the EuroQol five-dimensional questionnaire. Value Health. 2014;17(1):70-76. doi:10.1016/j.jval.2013.10.006

23. Hayes RP, DeLozier AM. Reliability, validity, and responsiveness of the Impact of Weight on Self-Perceptions Questionnaire (IW-SP) in individuals with type 2 diabetes and obesity. Diabetes Technol Ther. 2015;17(3):210-214. doi:10.1089/dia.2014.0142

24. Zhu L, Lui KJ. Prescott tests of equality in binary data under a three-treatment three-period crossover design. J Biopharm Stat. 2017;27(5):834-844. doi:10.1080/10543406.2016.1269785

25. Balkhi B, Alwhaibi M, Alqahtani N, et al. Oral antidiabetic medication adherence and glycaemic control among patients with type 2 diabetes mellitus: a cross-sectional retrospective study in a tertiary hospital in Saudi Arabia. BMJ Open. 2019;9(7):e029280. doi:10.1136/bmjopen-2019-029280 
26. Alyami M, Serlachius A, Mokhtar I, Broadbent E. Illness perceptions, HbA1c, and adherence in type 2 diabetes in Saudi Arabia. Patient Prefer Adherence. 2019;13:1839-1850. doi:10.2147/PPA. S228670

27. Rubin RR, Peyrot M. Quality of life and diabetes. Diabetes Metab Res Rev. 1999;15(3):205-218.

28. Trikkalinou A, Papazafiropoulou AK, Melidonis A. Type 2 diabetes and quality of life. World $J$ Diabetes. 2017;8(4):120-129. doi:10.4239/wjd.v8.i4.120

29. International Diabetes. Federation and the DAR International Alliance. Diabetes and Ramadan: practical Guidelines. April, 2016. Available from: www.idf.org/guidelines/diabetes-in-ramadan andwww.daralliance.org. Accessed October 17, 2020.

30. Al-Balhan E, Khabbache H, Laaziz A, et al. To fast or not to fast during the month of Ramadan? A comprehensive survey on religious beliefs and practices among Moroccan diabetic patients. Diabetes Metab Syndr Obes. 2018;11:633-640. doi:10.2147/DMSO.S171990

31. Abid M, Hsairi M, Elleuch M, Ben Aissa E. Survey on diabetic patients treated with insulin during the fasting month of Ramadan. Int J Gen Med. 2018;11:33-40. doi:10.2147/IJGM.S131308
32. Jabbar A, Hassanein M, Beshyah SA, Boye KS, Yu M, Babineaux SM. CREED study: hypoglycaemia during Ramadan in individuals with type 2 diabetes mellitus from three continents. Diabetes Res Clin Pract. 2017;132:19-26. doi:10.1016/j. diabres.2017.07.014

33. Gelhorn HL, Bacci ED, Poon JL, Boye KS, Suzuki S, Babineaux SM. Evaluating preferences for profiles of glucagon-like peptide-1 receptor agonists among injection-naive type 2 diabetes patients in Japan. Patient Prefer Adherence. 2016;10:1337-1348. doi:10.2147/PPA. S109289

34. Gelhorn HL, Poon JL, Davies EW, Paczkowski R, Curtis SE, Boye KS. Evaluating preferences for profiles of GLP-1 receptor agonists among injection-naive type 2 diabetes patients in the UK. Patient Prefer Adherence. 2015;9:1611-1622. doi:10.2147/PPA. S90842

35. Alqurashi KA, Aljabri KS, Bokhari SA. Prevalence of diabetes mellitus in a Saudi community. Ann Saudi Med. 2011;31(1):19-23. doi:10.4103/0256-4947.75773

\section{Publish your work in this journal}

Patient Preference and Adherence is an international, peer-reviewed, open access journal that focusing on the growing importance of patient preference and adherence throughout the therapeutic continuum. Patient satisfaction, acceptability, quality of life, compliance, persistence and their role in developing new therapeutic modalities and compounds to optimize clinical outcomes for existing disease states are major areas of interest for the journal. This journal has been accepted for indexing on PubMed Central. The manuscript management system is completely online and includes a very quick and fair peer-review system, which is all easy to use. Visit http:// www.dovepress.com/testimonials.php to read real quotes from published authors. 